\title{
Vitamin D Insufficiency May Account for Almost Nine of Ten COVID-19 Deaths: Time to Act. Comment on: "Vitamin D Deficiency and Outcome of COVID-19 Patients". Nutrients 2020, 12, 2757
}

\author{
Hermann Brenner ${ }^{1,2, *(1)}$ and Ben Schöttker ${ }^{1,2}$ (B) \\ 1 Division of Clinical Epidemiology and Aging Research, German Cancer Research Center, \\ 69120 Heidelberg, Germany; b.schoettker@dkfz.de \\ 2 Network Aging Research, University of Heidelberg, 69120 Heidelberg, Germany \\ * Correspondence: h.brenner@dkfz.de; Tel.: +49-6221-42-1300
}

Received: 19 October 2020; Accepted: 5 November 2020; Published: 27 November 2020

Evidence from observational studies is accumulating, suggesting that the majority of deaths due to SARS-CoV-2 infections are statistically attributable to vitamin D insufficiency and could potentially be prevented by vitamin D supplementation. Given the dynamics of the COVID-19 pandemic, rational vitamin D supplementation whose safety has been proven in an extensive body of research should be promoted and initiated to limit the toll of the pandemic even before the final proof of efficacy in preventing COVID-19 deaths by randomized trials.

We read, with great interest, the recent article by Radujkovic et al. that reported associations between vitamin D deficiency $(25(\mathrm{OH}) \mathrm{D}<12 \mathrm{ng} / \mathrm{mL})$ or insufficiency $(25(\mathrm{OH}) \mathrm{D}<20 \mathrm{ng} / \mathrm{mL})$ and death in a cohort of 185 consecutive symptomatic SARS-CoV-2-positive patients admitted to the Medical University Hospital Heidelberg, who were diagnosed and treated between 18 March and 18 June 2020 [1]. In this cohort, 118 patients (64\%) had vitamin D insufficiency at recruitment (including 41 patients with vitamin D deficiency), and 16 patients died of the infection. With a covariate-adjusted relative risk of death of 11.3, mortality was much higher among vitamin D insufficient patients than among other patients. When translated to the proportion of deaths in the population that is statistically attributable to vitamin D insufficiency ("population attributable risk proportion"), a key measure of public health relevance of risk factors [2], these results imply that $87 \%$ of COVID-19 deaths may be statistically attributed to vitamin $\mathrm{D}$ insufficiency and could potentially be avoided by eliminating vitamin D insufficiency.

Although results of an observational study, such as this one, need to be interpreted with caution, as done by the authors [1], due to the potential of residual confounding or reverse causality (i.e., vitamin D insufficiency resulting from poor health status at baseline rather than vice versa), it appears extremely unlikely that such a strong association in this prospective cohort study could be explained this way, in particular as the authors had adjusted for age, sex and comorbidity as potential confounders in their multivariate analysis. There are also multiple plausible mechanisms that may well explain the observed associations, such as increased concentrations of pro-inflammatory cytokines, as well as decreased concentrations of anti-inflammatory cytokines in vitamin D insufficiency [3,4]. Although final proof of causality and prevention of deaths by vitamin D supplementation would have to come from randomized trials which meanwhile have been initiated (e.g., [5]), the results of such trials will not be available in the short run. Given the dynamics of the COVID-19 pandemic and the proven safety of vitamin D supplementation, it therefore appears highly debatable and potentially even unethical to await results of such trials before public health action is taken. Besides other population-wide measures of prevention, widespread vitamin $\mathrm{D}_{3}$ supplementation at least for high-risk groups, such as older 
adults or people with relevant comorbidity, which has been proven by randomized controlled trials to be beneficial with respect to prevention of other acute respiratory infections and acute acerbation of asthma and chronic pulmonary disease [6-10], should be promoted. In addition, targeted vitamin $\mathrm{D}_{3}$ supplementation of people tested SARS-CoV-2-positive may be warranted.

Author Contributions: H.B. drafted the manuscript and B.S. provided constructive critical feedback. Both authors have read and agreed to the published version of the manuscript.

Funding: This research received no external funding.

Conflicts of Interest: The authors declare no competing financial interest.

\section{References}

1. Radujkovic, A.; Hippchen, T.; Tiwari-Heckler, S.; Dreher, S.; Boxberger, M.; Merle, U. Vitamin D Deficiency and Outcome of COVID-19 Patients. Nutrients 2020, 12, 2757. [CrossRef] [PubMed]

2. Benichou, J. A review of adjusted estimators of attributable risk. Stat. Methods Med. Res. 2001, 10, $195-216$. [CrossRef] [PubMed]

3. Grant, W.B.; Lahore, H.; McDonnell, S.L.; Baggerly, C.A.; French, C.B.; Aliano, J.L.; Bhattoa, H.P. Evidence that Vitamin D Supplementation Could Reduce Risk of Influenza and COVID-19 Infections and Deaths. Nutrients 2020, 12, 988. [CrossRef] [PubMed]

4. Brenner, H.; Holleczek, B.; Schöttker, B.; Vitamin, D. Insufficiency and Deficiency and Mortality from Respiratory Diseases in a Cohort of Older Adults: Potential for Limiting the Death Toll during and beyond the COVID-19 Pandemic? Nutrients 2020, 12, 2488. [CrossRef] [PubMed]

5. Wang, R.; DeGruttola, V.; Lei, Q.; Mayer, K.H.; Redline, S.; Hazra, A.; Mora, S.; Willett, W.C.; Ganmaa, D.; Manson, J.E. The vitamin D for COVID-19 (VIVID) trial: A pragmatic cluster-randomized design. Contemp. Clin. Trials 2020, 106176. [CrossRef] [PubMed]

6. Martineau, A.R.; Jolliffe, D.A.; Hooper, R.L.; Greenberg, L.; Aloia, J.F.; Bergman, P.; Dubnov-Raz, G.; Esposito, S.; Ganmaa, D.; Ginde, A.A.; et al. Vitamin D supplementation to prevent acute respiratory tract infections: Systematic review and meta-analysis of individual participant data. BMJ 2017, 356, i6583. [CrossRef] [PubMed]

7. Jolliffe, D.A.; Greenberg, L.; Hooper, R.L.; Griffiths, C.J.; Camargo, C.A., Jr.; Kerley, C.P.; Jensen, M.E.; Mauger, D.; Stelmach, I.; Urashima, M.; et al. Vitamin D supplementation to prevent asthma exacerbations: A systematic review and meta-analysis of individual participant data. Lancet Respir. Med. 2017, 5, 881-890. [CrossRef]

8. Jolliffe, D.A.; Greenberg, L.; Hooper, R.L.; Mathyssen, C.; Rafiq, R.; de Jongh, R.T.; Camargo, C.A.; Griffiths, C.J.; Janssens, W.; Martineau, A.R. Vitamin D to prevent exacerbations of COPD: Systematic review and meta-analysis of individual participant data from randomised controlled trials. Thorax 2019, 74, 337-345. [CrossRef] [PubMed]

9. Keum, N.; Lee, D.H.; Greenwood, D.C.; Manson, J.E.; Giovannucci, E. Vitamin D supplementation and total cancer incidence and mortality: A meta-analysis of randomized controlled trials. Ann. Oncol. 2019, 30, 733-743. [CrossRef] [PubMed]

10. Vaughan-Shaw, P.G.; Buijs, L.F.; Blackmur, J.P.; Theodoratou, E.; Zgaga, L.; Din, F.V.N.; Farrington, S.M.; Dunlop, M.G. The effect of vitamin D supplementation on survival in patients with colorectal cancer: Systematic review and meta-analysis of randomised controlled trials. Br. J. Cancer 2020. [CrossRef] [PubMed]

Publisher's Note: MDPI stays neutral with regard to jurisdictional claims in published maps and institutional affiliations.

(C) 2020 by the authors. Licensee MDPI, Basel, Switzerland. This article is an open access article distributed under the terms and conditions of the Creative Commons Attribution (CC BY) license (http://creativecommons.org/licenses/by/4.0/). 